\title{
Quantum Size Effect in ZnO Nanoparticles via Mechanical Milling
}

\author{
Nurul Azri Khalisah Aznan and Mohd Rafie Johan \\ Advanced Materials Research Laboratory, Department of Mechanical Engineering, University of Malaya, Lembah Pantai, \\ 50603 Kuala Lumpur, Malaysia
}

Correspondence should be addressed to Nurul Azri Khalisah Aznan, nurulazri@siswa.um.edu.my

Received 7 July 2011; Revised 15 September 2011; Accepted 16 September 2011

Academic Editor: William W. Yu

Copyright ( $) 2012$ N. A. K. Aznan and M. R. Johan. This is an open access article distributed under the Creative Commons Attribution License, which permits unrestricted use, distribution, and reproduction in any medium, provided the original work is properly cited.

\begin{abstract}
$\mathrm{ZnO}$ nanocrystals were successfully produced by mechanical milling. It is shown that mechanical milling is very effective and simple to produce $\mathrm{ZnO}$ nanoparticles with the possibility of obtaining large quantities of materials. Size effects in $\mathrm{ZnO}$ nanoparticles were probed by XRD and UV-vis and photoluminescence (PL) spectroscopy. Absorption due to free electron was clearly observed, whereas strong PL lines were recorded in the UV and blue region. The absorbance and photoluminescence were found to increase with reduction in particle size. Blueshift of excitonic and emission peaks was observed as a consequence of the size quantization effect. Formation of pure $\mathrm{ZnO}$ phase was confirmed from XRD pattern and the optical spectroscopy.
\end{abstract}

\section{Introduction}

Compared to bulk materials, nanoscale materials exhibit large specific surface area and size-dependent quantum confinement effects. Nanoscale materials often have distinct electronic, optical, magnetic, catalytic, and thermal properties. They provide a unique opportunity to observe the evolving electronic structure of materials growing from molecules to bulk. The investigations on size-dependent electronic structure have revealed interesting properties including discretization of electron energy levels, concentration of oscillator strength, highly polarizable excited states, and increased electron-electron correlation [1-4]. $\mathrm{ZnO}$ nanoparticles are one of the important multifunctional materials due to their unique optical and electronic properties [5-9]. It has a wide band gap semiconductor, having high exciton binding energy of $60 \mathrm{meV}$ and has stable wurtzite structure with lattice spacing $a=0.325 \mathrm{~nm}$ and $c=0.521 \mathrm{~nm}$. Several authors have reported high photoluminescence (PL) efficiencies in $\mathrm{ZnO}$ nanostructures [10, 11]. Optical techniques are the most common techniques to study the quantum size effects. Here, we report studies on the optical properties of zinc oxide $(\mathrm{ZnO})$ nanoparticles, synthesized by a mechanical route. We have emphasized UV-vis and PL spectroscopic studies, to examine the size-induced effects.
Various techniques have been used to synthesis $\mathrm{ZnO}$ nanoparticles including mechanical milling [12], hydrothermal synthesis [13], sol-gel method [14], and spray pyrolysis [10].

\section{Experimental}

Commercially obtained $\mathrm{ZnO}$ powder with size $\sim 200 \mathrm{~nm}$ and purity $99 \%$ was milled in a zirconia jar with zirconia balls with a ball-to-powder weight ratio of 14 . The mechanical milling was performed in a horizontal ball mill operating at $200 \mathrm{rpm}$ for different milling times $(5,10,15$, and $20 \mathrm{~h})$. No solvent was used in this process.

The optical properties were investigated by using Cary, 50-probe UV-vis spectrophotometer, and Perkin Elmer (LS55) Luminescence Spectrophotometer (PL). X-ray diffraction patterns were performed using SIEMEN D500 X-ray diffractometer equipped with graphite monochromatized $\mathrm{Cu}$ $\mathrm{K} \alpha$ radiation $(\lambda=1.5418 \AA$ \& $)$ irradiated with a scanning rate of $0.02^{\circ} \mathrm{s}^{-1}$. The particle size was calculated from the effective mass equation using data from UV-vis spectroscopy.

\section{Results and Discussion}

Figure 1 shows the XRD pattern of the $\mathrm{ZnO}$ powders before and after milling. All the peaks corresponding to the 


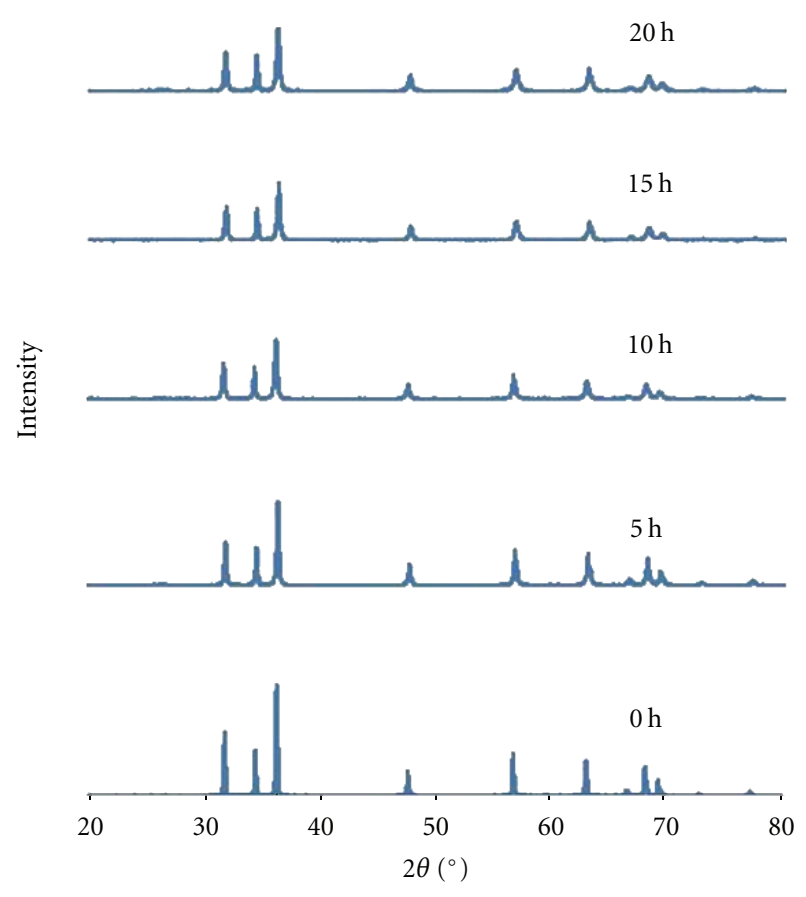

FIGURE 1: XRD pattern for $\mathrm{ZnO}$ particles before and after milling.

reflections of hexagonal phase $\mathrm{ZnO}$ match well with standard diffraction data (JCPDS card no. 80-0075), as well as with that for high-purity powder. With increasing milling time, the corresponding peaks become less intense and broader. No major change is observed on the lattice parameters. The considerably broad reflections are mainly a consequence of a small grain size with a small contribution from internal strain induced by the severe mechanical deformation.

Figure 2 shows the UV absorption spectra of $\mathrm{ZnO}$ powders milled at different milling times. Absorption peaks corresponding to $5,10,15$, and $20 \mathrm{~h}$ are obtained at 284.97, 281.98, 279.94, and $276.95 \mathrm{~nm}$, respectively. As seen from Figure 2, the absorption spectra for all the samples show sharp excitonic peaks and blue shifted due to quantum confinement effect. The absorbance increases as the milling time increases. Therefore, the optical properties get enhanced with the increasing ratio of surface to volume in $\mathrm{ZnO}$ powder.

The particle size was determined from the effective mass equation below [13]:

$$
E=E_{\text {bulk }}+h^{2} \pi^{2}\left(\frac{1}{m_{e}}+\frac{1}{m_{h}}\right)-\frac{\left(1.8 e^{2}\right)}{4 \pi \varepsilon^{\prime} \varepsilon_{0}^{\prime} R},
$$

where $E$ and $E_{\text {bulk }}$ are the band gap of synthesized and bulk $(3.3 \mathrm{eV}) \mathrm{ZnO}$ particles, respectively, $R$ is radius of the particle, $m_{e}$ is the effective mass of electron $\left(0.28 m_{0}\right), m_{h}$ is the effective mass of hole $\left(0.49 m_{0}\right), \varepsilon^{\prime}$ is the dielectric constant of material (2.1), $\varepsilon_{0}^{\prime}$ is the permittivity of free space, and $h$ is the Planck's constant.

Table 1 shows the size of $\mathrm{ZnO}$ particles are decreases as the milling time increases.

Figure 3 shows the room temperature photoluminescence (PL) spectra of $\mathrm{ZnO}$ nanoparticles milled for 5, 10,

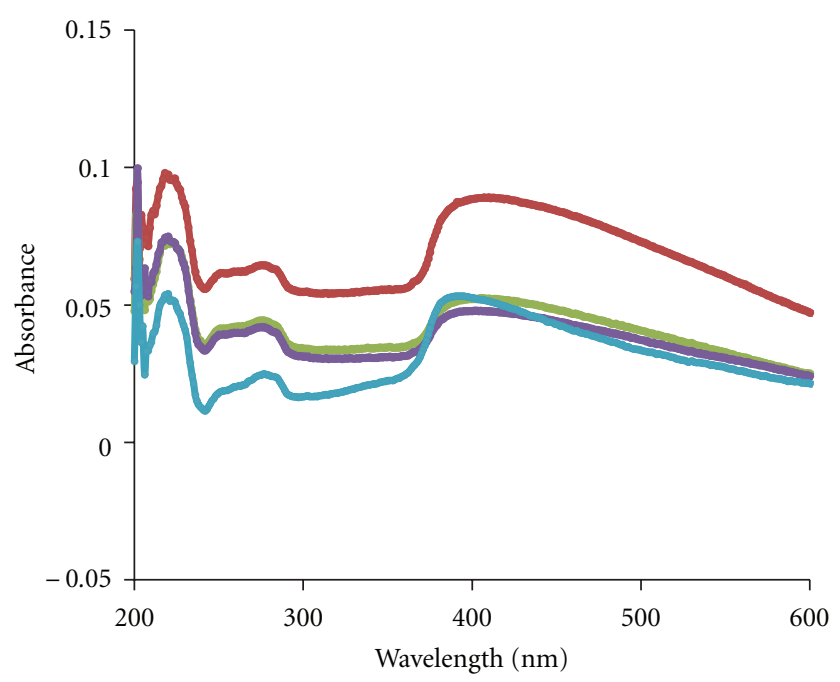

(a)

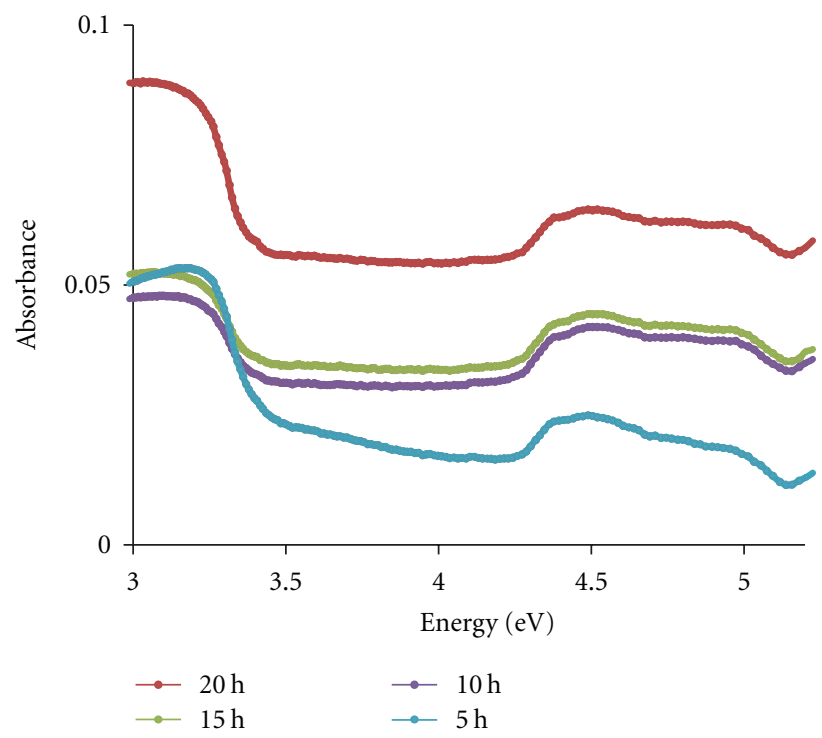

(b)

FIGURE 2: UV-vis spectra of $\mathrm{ZnO}$ nanoparticles at various milling times with respect to their (a) wavelength and (b) energy.

TABLE 1: Characteristics of $\mathrm{ZnO}$ powders at various milling times.

\begin{tabular}{lcccc}
\hline $\begin{array}{l}\text { Milling } \\
\text { time }(\mathrm{h})\end{array}$ & $\begin{array}{c}\text { FWHM } \\
(\mathrm{eV})\end{array}$ & $\begin{array}{c}\text { UV emission } \\
\text { peak }(\mathrm{nm})\end{array}$ & $\begin{array}{c}\text { BE emission } \\
\text { peak }(\mathrm{nm})\end{array}$ & $\begin{array}{c}\text { Particle size } \\
\text { from }(1)(\mathrm{nm})\end{array}$ \\
\hline 5 & 0.46 & 309.0 & 414.0 & 2.32 \\
10 & 0.51 & 308.5 & 430.0 & 2.24 \\
15 & 0.52 & 306.5 & 418.0 & 2.18 \\
20 & 0.54 & 307.0 & 417.5 & 2.10 \\
\hline
\end{tabular}

15, and $20 \mathrm{~h} . \mathrm{ZnO}$ nanoparticles exhibited two prominent emission PL bands at around 309 and $418 \mathrm{~nm}$. The PL peak at $309 \mathrm{~nm}$ which is intense and sharp is assigned to near-band-edge emission (UV emission) attributed to free electron recombination [15]. This peak intensity is decreased 


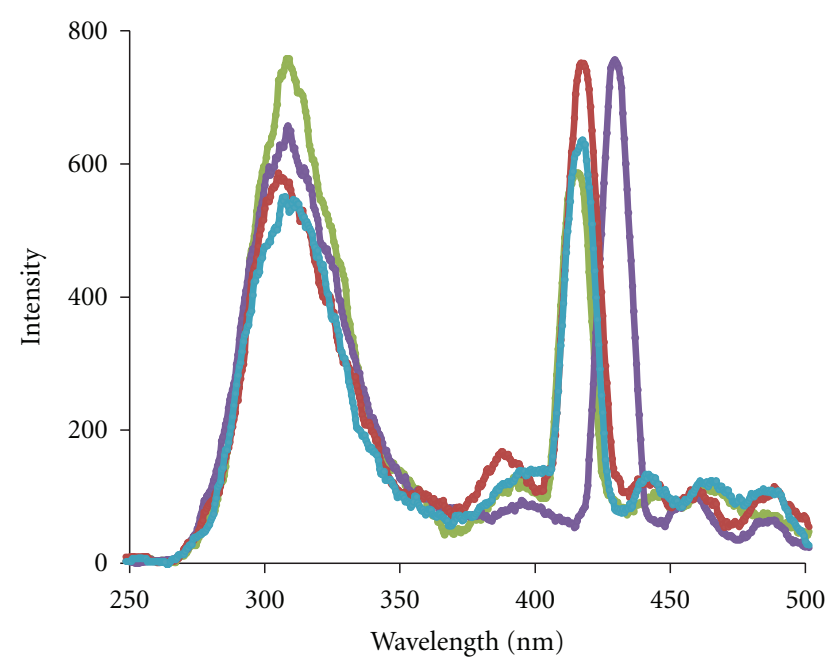

(a)

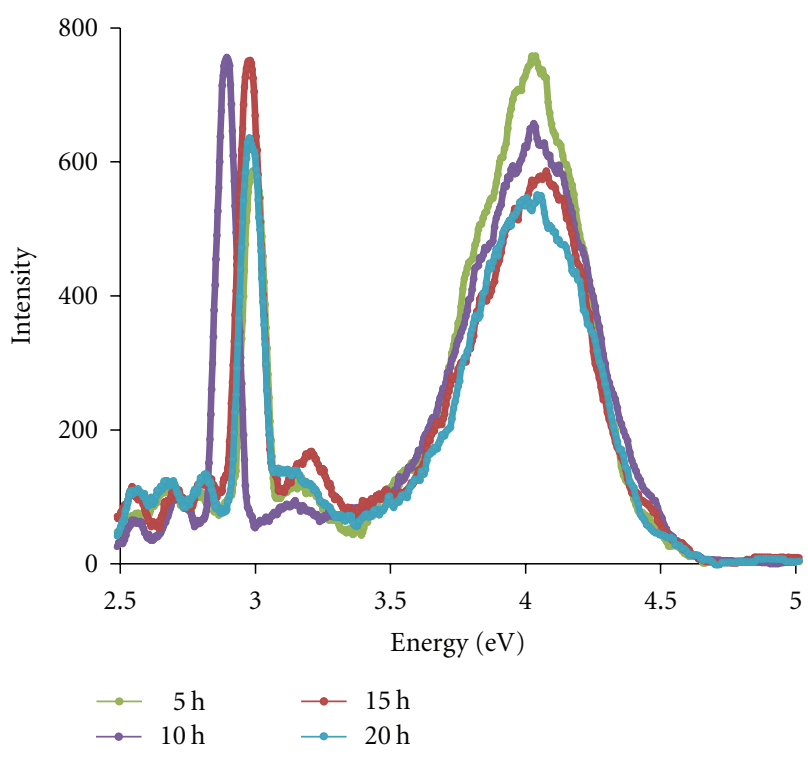

(b)

Figure 3: Photoluminscene spectra of $\mathrm{ZnO}$ powders at various milling time.

and blue shifted as the particle size decreases. Blue shift in the UV emission peak is due to the quantum confinement effect. The peak around $430 \mathrm{~nm}$ is blue emission (BE) which is attributed to intrinsic defects such as oxygen and zinc interstitials [16]. It can be observed that only small changes in the parameters are observed for the sample milled $20 \mathrm{~h}$, which is wider and less-quantum efficiency. The mechanical milling produces different kinds of defects in the powders giving place to an increase in the possible recombination mechanisms. Table 1 summarized the UV and PL characteristics of the samples.

\section{Conclusion}

$\mathrm{ZnO}$ nanoparticles were successfully synthesized at room temperature via mechanical milling. Absorption spectra demonstrate sharp excitonic peaks and blue shifted corresponding to quantum confinement effect. The absorbance was increased as the milling time increases. Strong PL lines were recorded in the UV and blue region. The crystal structure of $\mathrm{ZnO}$ nanoparticles is the same as that of bulk $\mathrm{ZnO}$, though some amount of internal strain induced by the severe mechanical deformation.

\section{Acknowledgment}

The authors gratefully acknowledge financial support from Ministry of Higher Education of Malaysia under Fundamental Research Grant Scheme FRGS Grant (no. FP015/2008C).

\section{References}

[1] A. D. Yoffe, "Low-dimensional systems: quantum size effects and electronic properties of semiconductor microcrystallites (zero-dimensional systems) and some quasi-two-dimensional systems," Advances in Physics, vol. 42, no. 2, pp. 173-266, 1993.

[2] Y. Kayanuma, "Quantum-size effects of interacting electrons and holes in semiconductor microcrystals with spherical shape," Physical Review B, vol. 38, no. 14, pp. 9797-9805, 1988.

[3] L. E. Brus, "Zero-dimensional "excitons" in semiconductor clusters," IEEE Journal of Quantum Electronics, vol. 22, no. 9, pp. 1909-1914, 1986.

[4] M. V. Rama Krishna and R. A. Friesner, "Exciton spectra of semiconductor clusters," Physical Review Letters, vol. 67, no. 5, pp. 629-632, 1991.

[5] T. Kumpika, W. Thongsuwan, and P. Singjai, "Optical and electrical properties of $\mathrm{ZnO}$ nanoparticle thin films deposited on quartz by sparking process," Thin Solid Films, vol. 516, no. 16, pp. 5640-5644, 2008.

[6] H. Yano, J. Sugiyama, A. N. Nakagaito et al., "Optically transparent composites reinforced with networks of bacterial nanofibers," Advanced Materials, vol. 17, no. 2, pp. 153-155, 2005.

[7] R. J. Nussbaumer, W. R. Caseri, P. Smith, and T. Tervoort, "Polymer- $\mathrm{TiO}_{2}$ nanocomposites: a route towards visually transparent broadband UV filters and high refractive index materials," Macromolecular Materials and Engineering, vol. 288, no. 1, pp. 44-49, 2003.

[8] V. Srikant and D. R. Clarke, "On the optical band gap of zinc oxide," Journal of Applied Physics, vol. 83, no. 10, pp. 54475451, 1998.

[9] A. Moballegh, H. R. Shahverdi, R. Aghababazadeh, and A. R. Mirhabibi, "ZnO nanoparticles obtained by mechanochemical technique and the optical properties," Surface Science, vol. 601, no. 13, pp. 2850-2854, 2007.

[10] A. K. Singh, S. B. Patil, and V. C. Janu, "Structural, optical and electrical characterization of nano-structured $\mathrm{ZnO}$ thin films deposited by solution growth technique," in Proceedings of the 8th IEEE Conference on Nanotechnology, (NANO '08), vol. 2, pp. 760-763, Arlington, Tex, USA, August 2008.

[11] L. C. Damonte, L. A. Mendoza Zélis, B. M. Soucase, and M. A. Hernández Fenollosa, "Nanoparticles of $\mathrm{ZnO}$ obtained by mechanical milling," Powder Technology, vol. 148, no. 1, pp. 15-19, 2004.

[12] A. Sasaki, W. Hara, A. Mastuda, N. Tateda, K. Saitom, and M. Yoshimoto, "Buffer-enhanced room-temperature growth and characterization of epitaxial $\mathrm{ZnO}$ thin films," Applied Physics Letters, vol. 86, no. 23, Article ID 231911, 3 pages, 2005. 
[13] A. Z. Sadek, W. Wlodarski, K. Kalantar-Zadeh et al., " $\mathrm{H}_{2}$ and $\mathrm{NO}_{2}$ gas sensors with $\mathrm{ZnO}$ nanobelt layer on $36 \circ \mathrm{LiTaO}_{3}$ and $64 \circ \mathrm{LiNbO}_{3} \mathrm{SAW}$ transducers," in Proceedings of the 4th IEEE Conference on Sensors, pp. 1343-1346, Irvine, Calif, USA, November 2005.

[14] M. K. Patra, K. Manzoor, M. Manoth, S. R. Vadera, and N. Kumar, "Studies of luminescence properties of $\mathrm{ZnO}$ and $\mathrm{ZnO}$ : $\mathrm{Zn}$ nanorods prepared by solution growth technique," Journal of Luminescence, vol. 128, no. 2, pp. 267-272, 2008.

[15] A. K. Singh, V. Viswanath, and V. C. Janu, "Synthesis, effect of capping agents, structural, optical and photoluminescence properties of $\mathrm{ZnO}$ nanoparticles," Journal of Luminescence, vol. 129, no. 8, pp. 875-878, 2009.

[16] A. Ghosh, N. G. Deshpande, Y. G. Gudage et al., "Effect of annealing on structural and optical properties of zinc oxide thin film deposited by successive ionic layer adsorption and reaction technique," Journal of Alloys and Compounds, vol. 469, no. 1-2, pp. 56-60, 2009. 

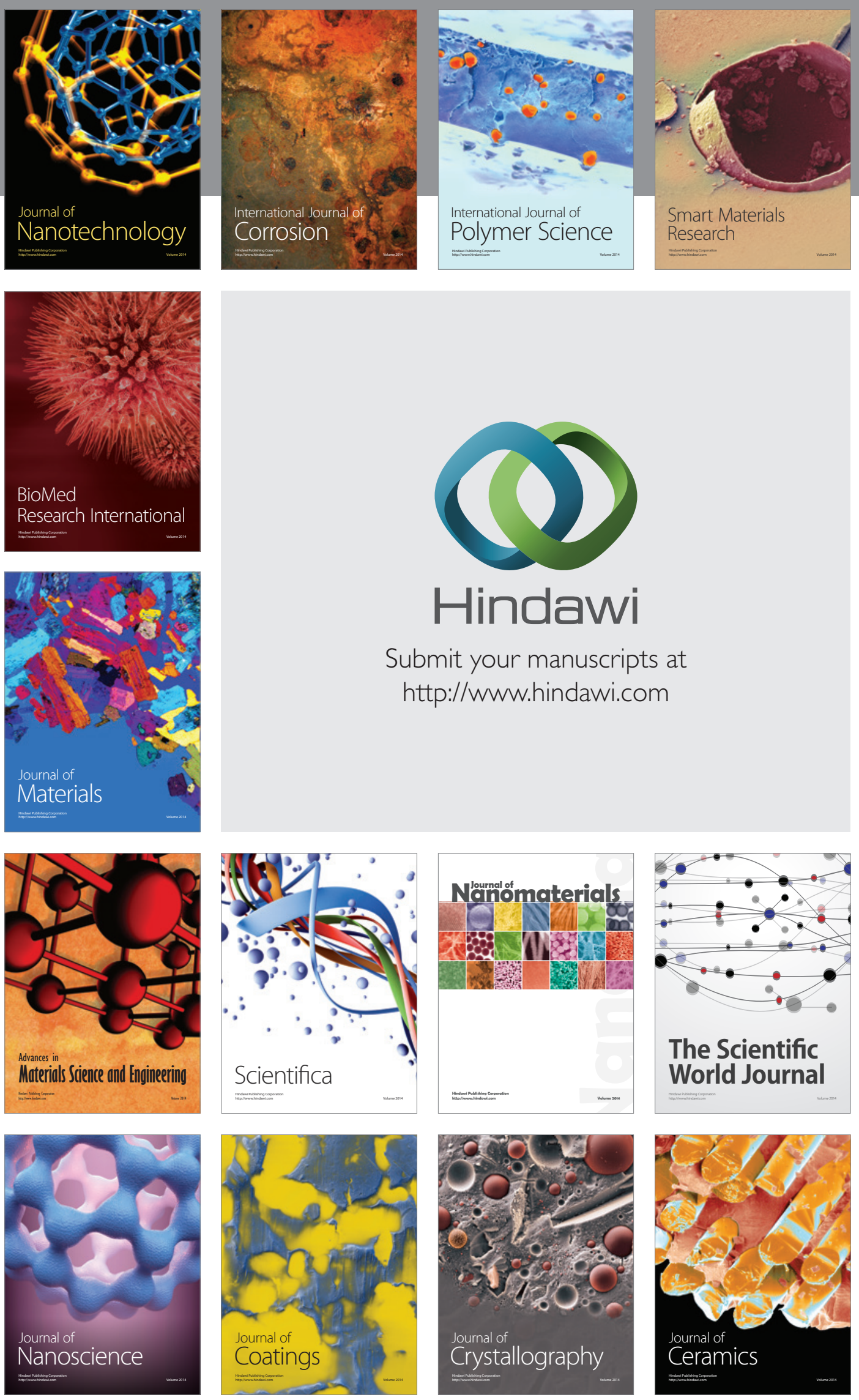

The Scientific World Journal

Submit your manuscripts at

http://www.hindawi.com

\section{World Journal}

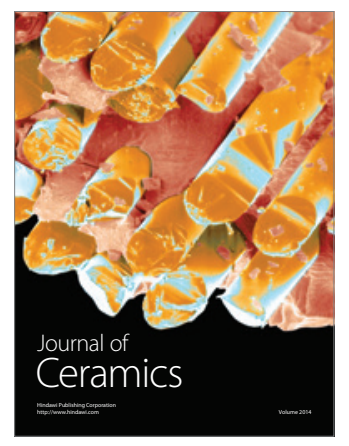

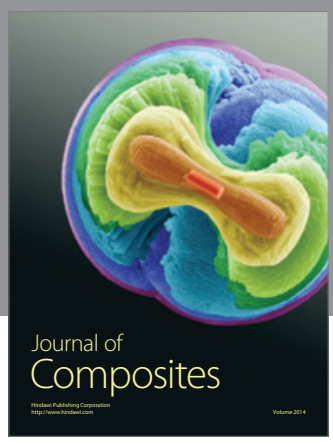
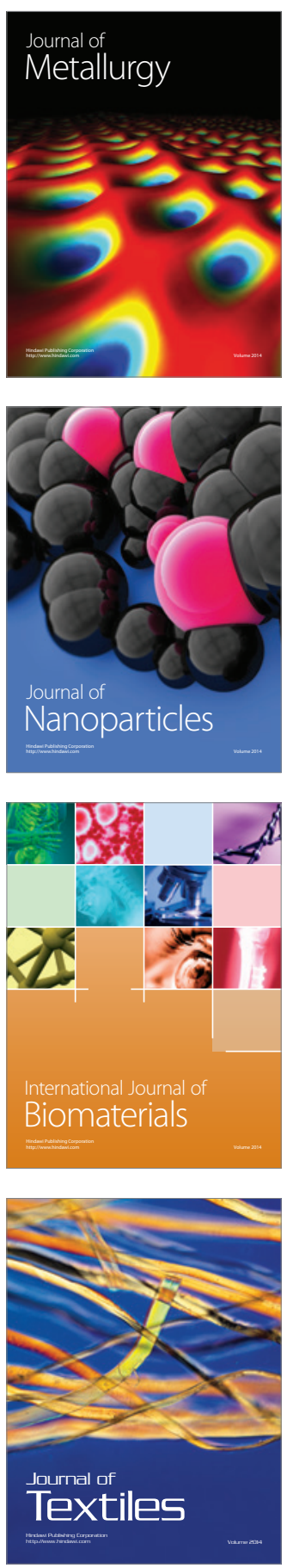